\title{
GROWTH STRESSES AND RELATED ANATOMICAL CHARACTERISTICS IN COCONUT PALM TREES
}

\author{
Ling-Long Kuo-Huang ${ }^{1}$, Yan-San Huang ${ }^{2}$, Shin-Shin Chen ${ }^{2}$ \& Yi-Ru Huang ${ }^{3}$
}

\begin{abstract}
SUMMARY
The surface growth strains and the distribution of internal stresses in woody palms, coconut (Cocos nucifera $\mathrm{L}$.), were determined by measuring the strains released by the kerf method using strain gauges. Measurements of the surface strains showed that longitudinal tensile stresses existed at the cortex, while longitudinal compressive stresses existed at the periphery of the central cylinder. These stresses may be generated from the fibers located in the scattered fiber and vascular bundles. In the central cylinder of narrow and wide trunks, both positive and negative stresses were observed, indicating the existence of some tensile and compressive stresses in the trunks. The amount of stress varied from base to top and from periphery to core because of the variation in proportion of the vascular bundles and the fibers, and the cell wall layers of fibers along these points. Furthermore, changes in the angle of vascular bundles and of the fiber microfibrils were correlated with the various tensile and compressive stresses located in the central cylinder of the trunks.
\end{abstract}

Key words: Cocos nucifera, growth strain, growth stress, vascular bundles, fibers, microfibril angle.

\section{INTRODUCTION}

The accumulation of growth stresses in woody plants is an unavoidable result of physiological adjustment during growth (Niklas 1992; Mattheck \& Kubler 1995). In response to heterogeneous growth stresses at the surface of the trunk, specific patterns of residual stresses are formed in the longitudinal, radial and tangential directions inside the trunk (Archer \& Bynes 1974; Kubler 1987; Fournier et al. 1990). During normal secondary growth in softwood and hardwood trees, vascular cambiums form xylem cells inwards and phloem cells outwards and the growth stresses accumulate year by year and form a regular distribution of the stresses. As a result, tensile stresses are formed in the outer

1) Department of Life Science, National Taiwan University, Roosevelt Road, Section 4, Taipei, Taiwan 106.

2) Division of Forest Utilization, Taiwan Forestry Research Institute, 53 Nan-Hai Road, Taipei, Taiwan 100.

3) College of Bioresources and Agriculture, Experimental Forest, National Taiwan University, Chien-Shan Road, Section 1, Chu-Shan, Nan-Tou, Taiwan 557.

*) Corresponding author: Dr. Yan-San Huang [E-mail: linglong@ntu.edu.tw]. 
part and compressive stresses in the inner part of a trunk, yielding a V-shaped stress distribution (Boyd, 1972; Yamamoto et al. 1991).

Previous studies have indicated that the production of stress was influenced by anatomical characteristics of the tissues, such as the microfibril angle of fibers, the degree of crystallinity of cells, and the lignin content of cell walls. The lignin-swelling hypothesis (Boyd 1972) and the cellulose-tension hypothesis (Bamber 1978) emerged to explain the initiation of growth stresses. However, these two hypotheses cannot explain both the growth stress of compression wood and the tensile stresses of normal and tension wood. Okuyama et al. (1986) combined the above-mentioned hypotheses as the unified hypothesis which could be applied to both normal and reaction wood. However, whether these hypotheses are applicable in monocotyledonous woody plants is still unknown.

The pattern of lateral thickening in monocotyledons is not understood as well as that in dicotyledons, partly because of the large variation of patterns within monocotyledons. Palm trees lack a lateral vascular cambium and do not increase stem diameter by division of cambium cells, unlike dicotyledonous, coniferous and certain other arborescent monocotyledonous trees (Tomlinson \& Zimmermann 1967). In the trunk of monocots, vascular bundles are scattered in the ground tissue to form an atactostele. This pattern is very different from the secondary growth of softwood and hardwood in which the growth stresses originate and accumulate from the process of lignification of newly formed xylem cells interior to the cambium. The measurement of growth stress of rattans (climbing palms; Abasolo et al. 1999) indicated that the distribution of growth stress was similar to that in the compression wood of conifers.

In palm trees, the internal growth stresses are initially set up when the tissues are produced but they change with the maturation of cells and tissues during secondary thickening. In our first report on palms (Huang et al. 2002), we showed that tensile stress existed longitudinally on the surface of vertically growing trunks, whereas compression stress was found at the bending position of leaning trunks. In the current work, the anatomical characteristics were studied of one narrow and several wide trunks, from base to top, and from periphery to core. We investigated proportions of vascular bundles and fibers, secondary wall layers of fibers, the angles of vascular bundles, and microfibril angles of the fiber cells. In addition to the anatomic characteristics, measurements were also made on the surface growth strains on cortex and periphery of the central cylinder, and the released growth strains inside the trunks.

\section{MATERIALS AND METHODS}

For this study, 20- to 25-year-old coconut trees (Cocos nucifera L.), growing in Hengchun $\left(120^{\circ} 49^{\prime} \mathrm{E}, 21^{\circ} 57^{\prime} \mathrm{N}\right.$, elevation $\left.230 \mathrm{~m}\right)$, Taiwan, were selected. These trees were chosen to have a range of stem with different diameters at breast height (DBH, 21.5 to $44.5 \mathrm{~cm}$ ) and roughly erectly growing trunks. The surface growth strains were measured following the procedures as in Huang et al. (2002). Strain gauges (10 mm long) were glued with cyanoacrylate adhesive in longitudinal and transverse directions on the cortex ( 36 trees) and on the periphery of the central cylinder (55 trees), all at 
breast height. With respect to the measurement of released surface growth strain, after calibrating the strain gauges to zero, the surface growth strain was released by the kerf method (Sasaki et al. 1978).

The released internal growth strains were measured at three heights on one narrow and one wide tree. The narrow tree was about $6 \mathrm{~m}$ in height and had diameters of 28.3, 23.5 and $22.5 \mathrm{~cm}$ at heights of $0.7,2.83$ and $4.91 \mathrm{~m}$, respectively. The wide tree was about $6.5 \mathrm{~m}$ in height with diameters of $34.5,30$ and $27 \mathrm{~cm}$ at heights of $1.5,3.45$ and $5.45 \mathrm{~m}$, respectively. In order to measure the internal growth strain at the three heights of these two trees, strain gauges were glued in the longitudinal direction along the diameter of each diametrical plank at intervals of $1.5 \mathrm{~cm}$. A diametrical plank is a radial board, 30 $\mathrm{cm}$ tall and $2 \mathrm{~cm}$ thick, and is made in the center portion of a log, $1.5 \mathrm{~m}$ long, with two ends still attached to the log (Huang et. al. 2002). The strain was measured as soon as the trunk was felled. To get the data of released growth stress, static bending modulus of elasticity (MOE) of the corresponding specimens was measured. The size of each specimen was $1 \times 1 \times 16 \mathrm{~cm}$. The growth stress was then calculated by multiplying the strain by the MOE. Specific gravity (oven-dry weight/green volume) of each internal strain-measured specimen was measured to show the within-trunk variation patterns. Besides, the density of vascular bundles (number $/ \mathrm{mm}^{2}$ ) of each specimen was also examined under the dissecting microscope. During preparation, samples were wrapped in plastic and stored at $4^{\circ}$ to keep for a short period.

Using free-hand sectioning or a sliding microtome, 25-45 $\mu \mathrm{m}$ thick cross sections were made from each of the internal strain-measured samples. For counting the secondary cell wall layers of fibers, sections were prepared for scanning electron microscopy (Cho et al. 2001). Fifty measurements of cell wall layers were counted on every sampling point. For measuring the diameters of vascular bundles and percentages of vascular bundle and fiber areas, the sections were stained with safranin $\mathrm{O}$ and fast green and then mounted on glass slides. The Image-Pro-Plus Analyzer was used for the measurements. Fifteen to sixty measurements were taken on every sampling point.

The angle of vascular bundles to the axis of the trunk was measured from the radial face of each of the internal strain-measured sample at basal trunk position. For each sample, twelve measurements were taken. The microfibril angle (MFA) of fibers was determined on the 25-35 $\mu \mathrm{m}$ thick tangential sections made from each of the internal strain-measured sample at basal trunk position and the surface strain-measured sample from the periphery of the central cylinder at breast height of the trunks. The sections were stained with $2 \%$ iodine solution for $1 \mathrm{~min}$ and observed at $60 \%$ nitric acid (Huang et al. 1997). For each sampling point, MFA of 50 fibers were measured.

\section{RESULTS AND DISCUSSION}

\section{Anatomical characteristics}

In coconut palm (Cocos nucifera), the major anatomical character of the trunk is the numerous vascular bundles scattering inside the ground tissue (Fig. 1a). The diameter of vascular bundles decreases not only from the base to the top but also from the core 

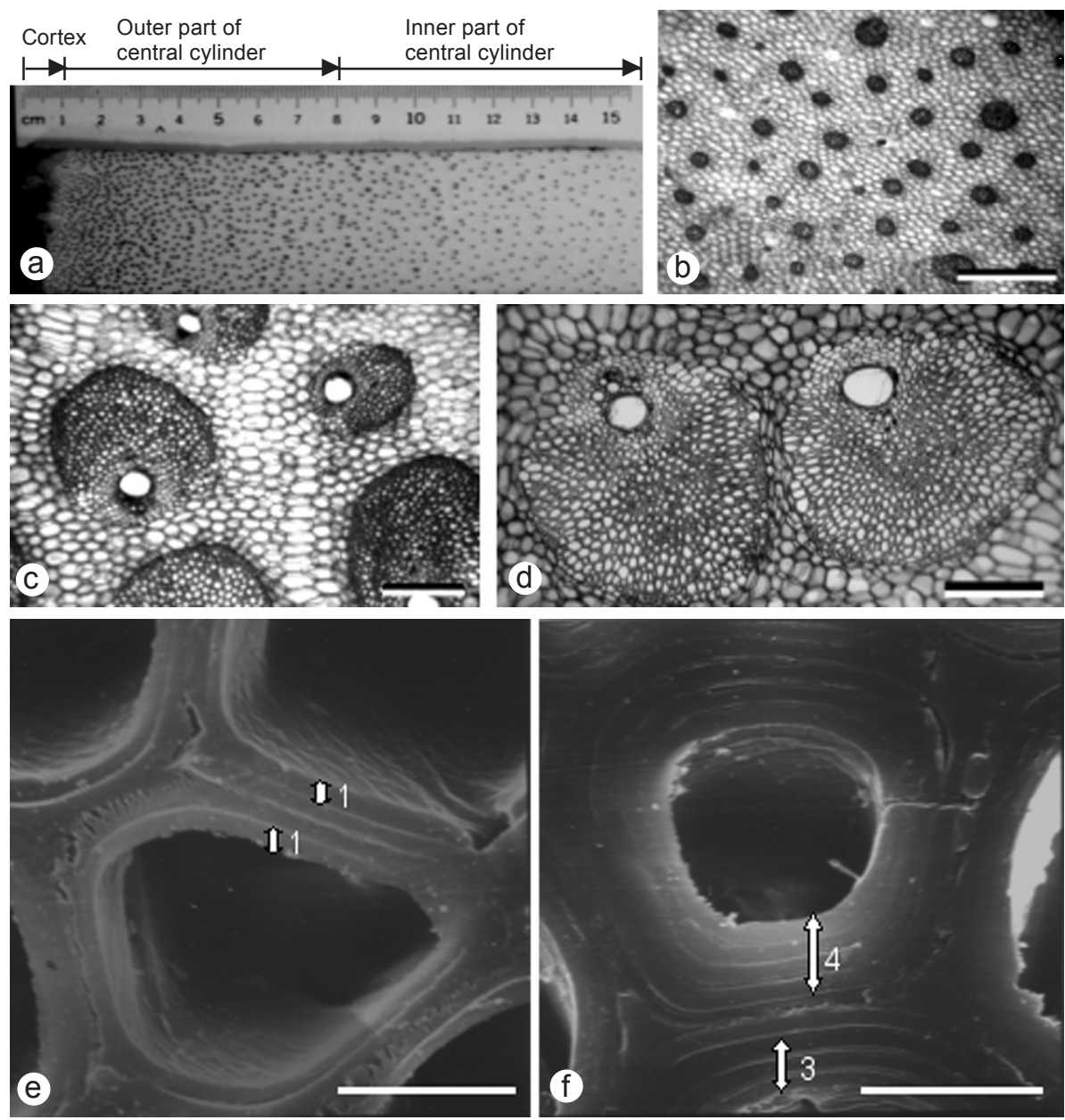

Fig.1. (a) Part of cross section of the basal part of the wide trunk of Cocos nucifera. The density of vascular bundles increased significantly from the core to the periphery. (b) The vascular bundles in the cortex, (c) the outer part of the central cylinder, and (d) the inner part of the central cylinder. (e) SEM of the cross section of fiber cells showing one layered secondary wall of the fibers in the cortex. (f) SEM of the cross section of fiber cells showing 3-and 4-layered secondary walls of the fibers in the outer part of the central cylinder. - Scale bars $=0.3 \mathrm{~mm}(\mathrm{~b}, \mathrm{c}, \mathrm{d})$, $6 \mu \mathrm{m}(\mathrm{e})$, and $10 \mu \mathrm{m}$ (f).

to the periphery (Fig. 1b-d \& Table 1). The density of vascular bundles increases from the core to the periphery and from the base to the top (Fig. 2a, b). The percentages of vascular bundle areas and fiber areas are significantly higher in the outer parts than in the inner parts of the central cylinder (Table 1).

The numbers of secondary wall layers in the fiber cells of the wide trunk (Fig. 1e, f) were mostly lower than those in the fiber cells of the corresponding positions of the 
Table 1. Results of Analysis of Variance (ANOVA). Diameter of vascular bundles (VB), percentage of the vascular bundle area, and percentage of fiber area on cross sections of the outer part of the central cylinder (OCC), and the inner part of the central cylinder (ICC) in one narrow and one wide palm trunk at basal, middle, and top positions.

\begin{tabular}{|c|c|c|c|c|c|c|c|c|c|c|c|}
\hline \multirow[t]{2}{*}{ Parameter } & \multicolumn{3}{|c|}{ OCC } & \multirow{2}{*}{$\begin{array}{c}\mathrm{T} \\
\text { test }\end{array}$} & \multicolumn{3}{|c|}{ ICC } & \multirow{2}{*}{$\begin{array}{c}\mathrm{T} \\
\text { test }\end{array}$} & \multirow{2}{*}{ OCC } & \multirow{2}{*}{ ICC } & \multirow{2}{*}{$\begin{array}{c}\mathrm{T} \\
\text { test }\end{array}$} \\
\hline & basal & middle & top & & basal & middle & top & & & & \\
\hline \multicolumn{12}{|c|}{ Narrow Trunk } \\
\hline \multicolumn{12}{|c|}{ VB diameter (mm) } \\
\hline mean & $0.78^{a}$ & $0.75^{\mathrm{a}}$ & $0.61^{\mathrm{b}}$ & ** & $1.07^{\mathrm{a}}$ & $0.93^{b}$ & $0.89^{\mathrm{b}}$ & $* *$ & 0.72 & 0.96 & - \\
\hline $\mathrm{n}$ & 60 & 60 & 60 & & 30 & 30 & 30 & & 180 & 90 & \\
\hline s.d. & 0.15 & 0.16 & 0.11 & & 0.15 & 0.18 & 0.12 & & 0.16 & 0.17 & \\
\hline \multicolumn{12}{|c|}{ VB area $(\%)$} \\
\hline mean & $43.73^{\mathrm{a}}$ & $53.46^{\mathrm{b}}$ & $56.25^{b}$ & ** & 33.72 & 36.75 & 36.59 & - & 51.15 & 35.74 & \\
\hline $\mathrm{n}$ & 30 & 30 & 30 & & 15 & 15 & 15 & & 90 & 45 & $* *$ \\
\hline s.d. & 7.52 & 6.53 & 7.06 & & 8.9 & 7.69 & 7.54 & & 8.81 & 8.06 & \\
\hline \multicolumn{12}{|c|}{ Fiber area (\%) } \\
\hline mean & $27.39^{\mathrm{a}}$ & $34.04^{b}$ & $34.65^{b}$ & ** & 20.21 & 19.85 & 18.26 & - & 32.03 & 19.44 & ** \\
\hline $\mathrm{n}$ & 30 & 30 & 30 & & 15 & 15 & 15 & & 90 & 45 & \\
\hline s.d. & 6.6 & 5.43 & 6.31 & & 5.73 & 4.17 & 4.56 & & 6.91 & 4.83 & \\
\hline \multicolumn{12}{|c|}{ Wide Trunk } \\
\hline \multicolumn{12}{|c|}{ VB diameter $(\mathrm{mm})$} \\
\hline mean & $0.89^{\mathrm{a}}$ & $0.88^{\mathrm{a}}$ & $0.68^{\mathrm{b}}$ & ** & $1.34^{\mathrm{a}}$ & $1.19^{\mathrm{b}}$ & $1.19^{\mathrm{b}}$ & ** & 0.82 & 1.24 & ** \\
\hline $\mathrm{n}$ & 60 & 60 & 60 & & 30 & 30 & 30 & & 180 & 90 & \\
\hline s.d. & 0.14 & 0.12 & 0.12 & & 0.13 & 0.12 & 0.10 & & 0.16 & 0.14 & \\
\hline s.d. & 6.6 & 5.43 & 6.31 & & 5.73 & 4.17 & 4.56 & & 6.91 & 4.83 & \\
\hline \multicolumn{12}{|c|}{ VB area $(\%)$} \\
\hline mean & 50.56 & 55.28 & 52.87 & - & 33.99 & 33.46 & 33.26 & - & 52.90 & 33.64 & ** \\
\hline $\mathrm{n}$ & 30 & 30 & 30 & & 15 & 15 & 15 & & 90 & 45 & \\
\hline s.d. & 8.36 & 5.73 & 8.47 & & 4.59 & 7.2 & 6.9 & & 7.78 & 6.3 & \\
\hline \multicolumn{12}{|c|}{ Fiber area (\%) } \\
\hline mean & $34.92^{\mathrm{ab}}$ & $38.31^{\mathrm{a}}$ & $32.44^{b}$ & ** & 21.86 & 22.39 & 21.40 & - & 35.23 & 21.89 & $* *$ \\
\hline $\mathrm{n}$ & 30 & 30 & 30 & & 15 & 15 & 15 & & 90 & 45 & \\
\hline s.d. & 7.06 & 4.37 & 8.4 & & 3.78 & 5.27 & 4.84 & & 7.16 & 4.58 & \\
\hline
\end{tabular}

-: $\mathrm{p}<0.05 ; * *: \mathrm{p}<0.01 ; \mathrm{n}$ : number of observation; s.d: standard deviation.

narrow trunk (Fig. 3a, b). Fibers have the ability to produce additional cell wall layers as they mature because they live throughout the life cycle of the palm (Tomlinson 1990). The addition of new secondary wall layers on fiber cells contributes to the stiffness and density of the palm trunk (Bhat et al. 1990).

The angles of vascular bundles with respect to the trunk axis were measured through the central cylinders of the basal diametrical planks (Fig. $4 \mathrm{a}-\mathrm{c}$ ). At the basal position of both the narrow and wide trunks, the angles of vascular bundles fluctuated centripetally. 

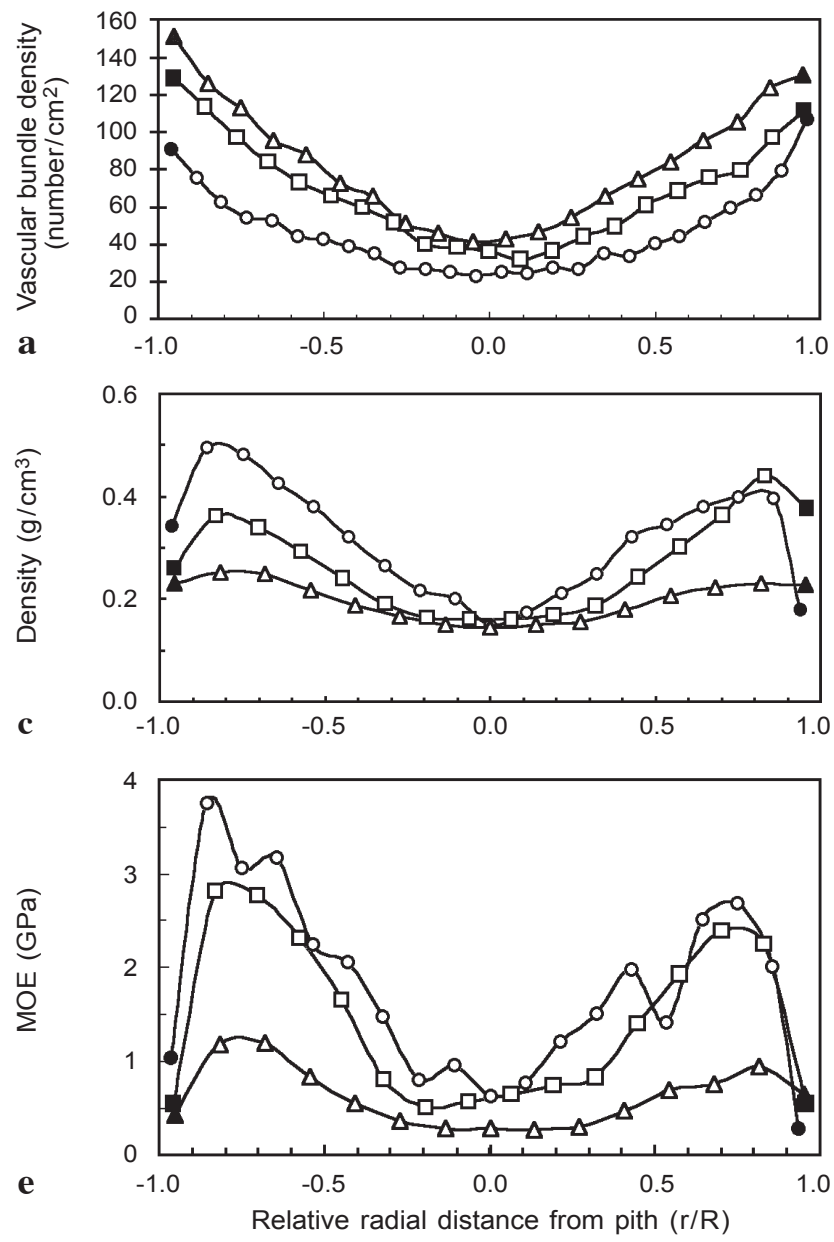

Fig. 2. (a, b) Distributions of vascular bundle density, (c, d) dry density, and (e, f) static bending modulus of elasticity (MOE) across the diametral planks of the narrow (a, c,e) and wide (b, d, f) trunks at the base ( $\bullet$ ), middle ( $\boldsymbol{\square})$ and top ( $\boldsymbol{\Delta})$ for the central cylinder (open symbols) and the cortex (black symbols).

In the basal part of the narrow trunk, the averages of microfibril angles (MFA) in the tangential surface of the individual fiber (Fig. $4 \mathrm{~d}, \mathrm{~g}$ ) ranged from $14^{\circ}$ to $38^{\circ}$, whereas in the wide trunk (Fig. 4e, f, h), they ranged from $18^{\circ}$ to $32^{\circ}$. For both the narrow and wide trunks, the angles at the cortex were above $30^{\circ}$, and then the angles fluctuated centripetally.

\section{Density and static bending modulus of elasticity (MOE) distribution}

The distribution of dry densities (specific gravities) of the narrow and wide trunks at all the three heights was lowest on the cortex and the inner parts of the central cylinder 

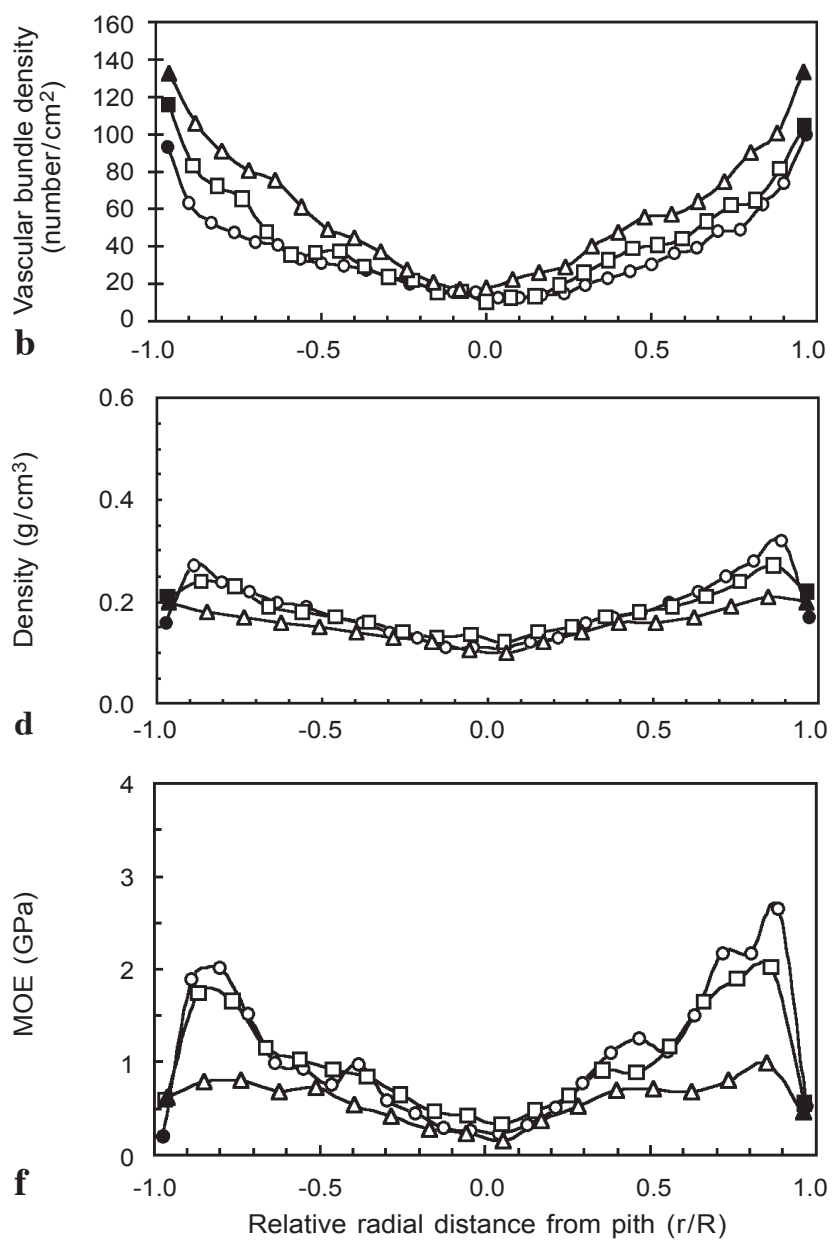

For legends, see previous page.

and highest on the outer part of the central cylinder like an 'M'-shape curve (Fig. 2c, d). In general, the densities were highest at the basal part. The lowest densities, about 0.1$0.2 \mathrm{~g} / \mathrm{cm}^{3}$, were found in the inner part of the cylinder at all three heights.

Density of wood is an excellent predictor of many mechanical properties of wood (Wangaard \& Muschler 1952; Rich 1987). The average density was $0.17 \pm 0.04 \mathrm{~g} / \mathrm{cm}^{3}$ (ranged from 0.10 to $0.32 \mathrm{~g} / \mathrm{cm}^{3}$ ) in the wider trunk and $0.26 \pm 0.08 \mathrm{~g} / \mathrm{cm}^{3}$ (ranged from 0.15 to $0.49 \mathrm{~g} / \mathrm{cm}^{3}$ ) in the narrow trunk. Because the strength of wood increases with increasing density (Kollmann \& Côté Jr. 1968), the narrow trunk can get the mechanical support from the greater wood strength. 


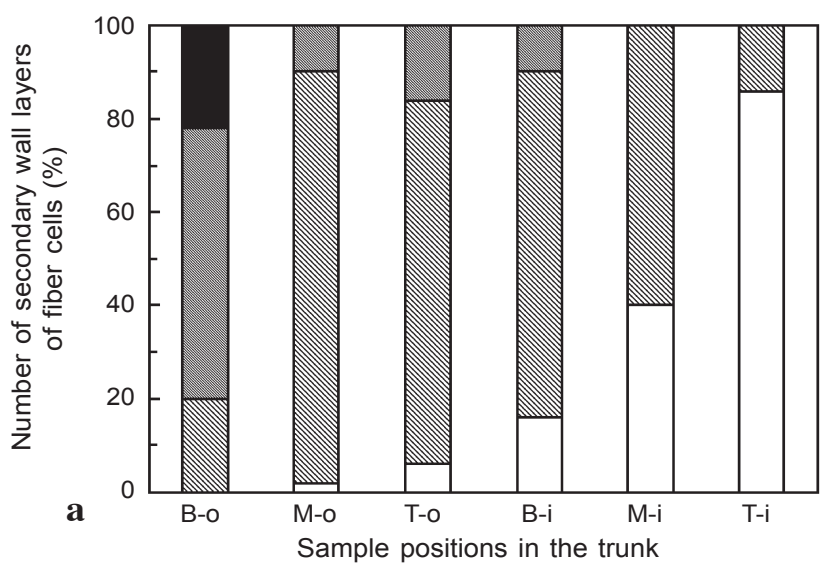

4 layers

涉 3 layers

$\mathbf{N} 2$ layers

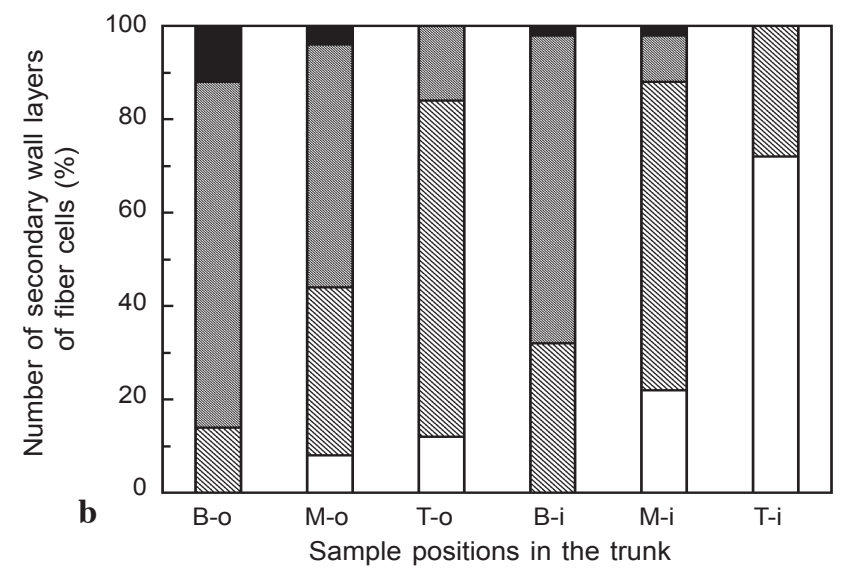

Fig. 3. Percentages of the numbers of secondary wall layers of fiber cells in the central cylinder of (a) the narrow and (b) the wide trunks at the outer base (B-o), outer middle (M-o), outer top (T-o), inner base (B-i), inner middle (M-i), and inner top (T-i) parts.

Bending modulus of elasticity (MOE) increased from the cortex to the periphery of the central cylinder and then decreased to the center of the central cylinder as well as from the base to the top (Fig. 2e, f). This observation is consistent with findings on six species of arborescent palms (Rich 1987). The greater elasticity on the outer part of the central cylinder than on the inner one will provide greater stiffness, and prevent the breakage of the trunk due to external forces such as wind.

\section{Surface growth strain of trunk}

Surface longitudinal and transverse growth strains were measured on the outside of the cortex and the central cylinder of the trunks with the range of stem diameters (Fig. 5). Similar to our first report on Cocos (Huang et al. 2002), the longitudinal and transverse surface growth strains on the outside of the cortex were mostly negative, 

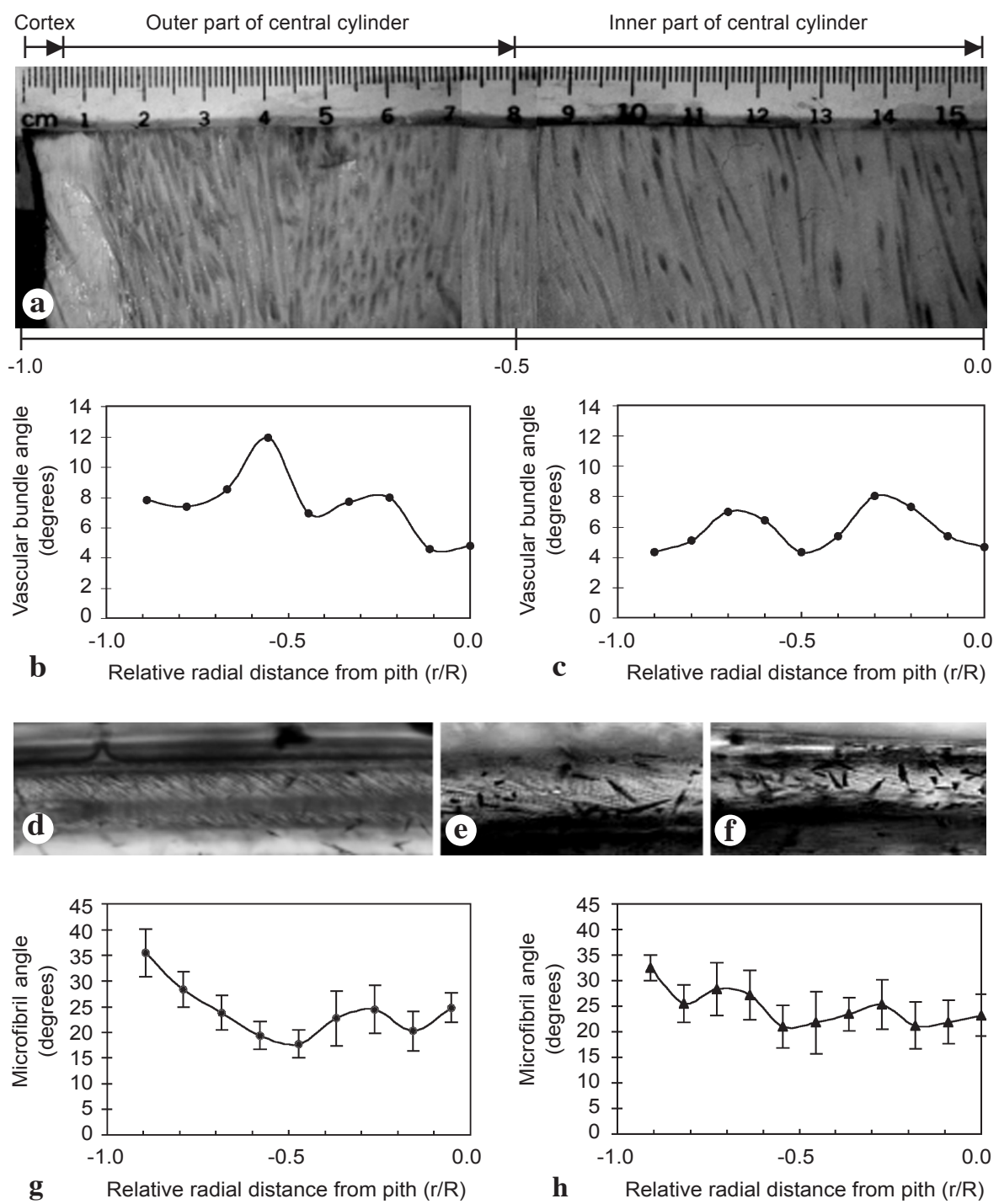

Fig. 4. (a) Part of a radial diametral plank of the wide trunk showing the orientation of vascular bundles. Distribution of the average angles of vascular bundles across the diametral planks of (b) the narrow and (c) the wide trunk. The microfibrils distributed in the secondary wall of fibers in (d) the cortex, (e) the outer part of the central cylinder, and (f) the inner part of the central cylinder of the narrow trunk. Distribution of the average microfibril angles of the fibers across the diametral planks of $(\mathrm{g})$ the narrow and $(\mathrm{h})$ the wide trunk.

indicating the existence of tensile stress (Fig. 5a). Fewer than $10 \%$ of the data (only four in the longitudinal direction and three in the transverse direction) were positive strains (between $44 \times 10^{-6}$ and $577 \times 10^{-6}$ ). Although these positive strains were mostly from the narrower trunks, there was no significant relationship between growth strain 

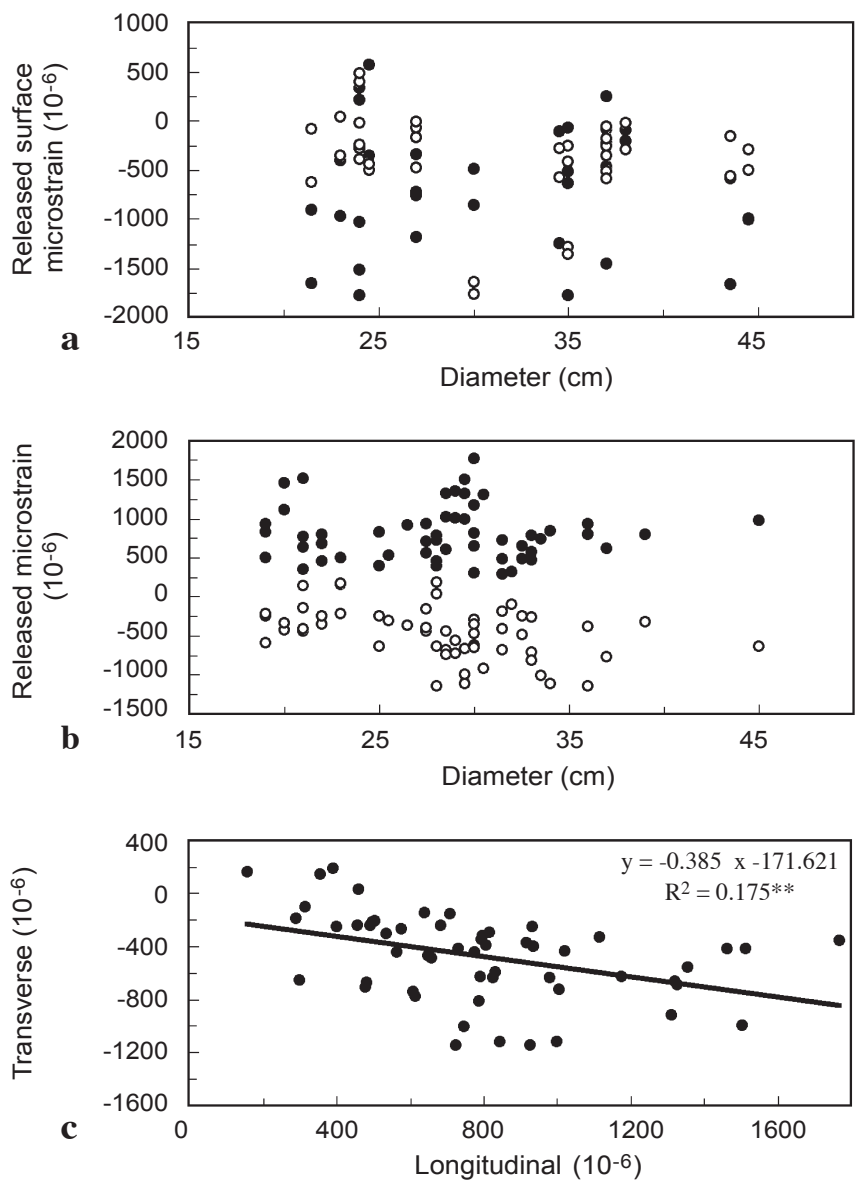

Fig. 5. Longitudinal (black symbols) and transverse (open symbols) surface growth strains on (a) the cortex and (b) the periphery of the central cylinder at breast height of various diameters of trunks. (c) Relation of transverse strains and longitudinal strains for samples from the periphery of the central cylinder.

and diameter (one-way analysis of variance). The average longitudinal and transverse growth strains on the cortex were $-645 \times 10^{-6}$ and $-392 \times 10^{-6}$, respectively. The cortex of the coconut palm trunk has similar released growth strains as the inner bark of dicotyledonous and coniferous trees (Okuyama et al. 1981). However, their structure and growth are very dissimilar.

On the periphery of the central cylinder of palm trunks, all the released longitudinal growth strains were positive (Fig. 5b), indicating compression stress. Most of the growth strains in transverse directions were negative, indicating tensile stress. However, owing to the different signs of longitudinal and transverse strains, compressive stress may occur in some cases after consideration of the effect of Poisson's ratio (Huang et al. 2001). Longitudinal surface strains varied significantly with transverse surface strains 

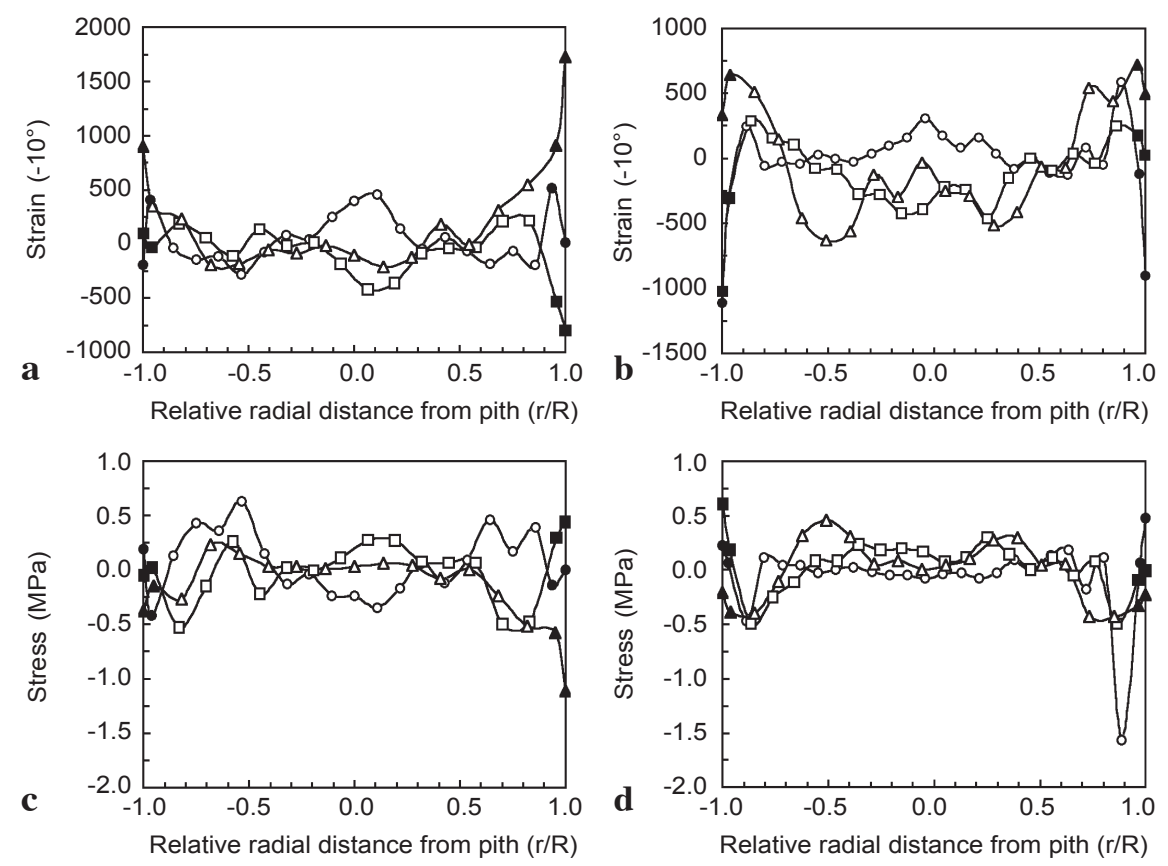

Fig. 6. Distributions of (a, b) growth strains and (c, d) stresses across the diametral planks of $(\mathrm{a}, \mathrm{c})$ the narrow and $(\mathrm{b}, \mathrm{d})$ the wide trunk at base $(\bullet)$, middle $(\boldsymbol{\square})$ and top $(\boldsymbol{\Delta})$ parts for the surface and cortex (black symbols) and the central cylinder (open symbols).

(ANOVA, Fig. 5c). This result is quite different from the cases of softwood and hardwood. Nevertheless, the anatomical structure and the longitudinal compressive growth stresses on the peripheral central cylinder of the palm trunks are similar to those on the periphery of rattan canes (Abasolo et al. 1999).

\section{Distribution of internal growth strains and stresses}

The longitudinal internal growth strains and stresses of the narrow and wide trunks at basal, middle and top positions are presented in Figure 6. The growth strain or stress (black symbols) indicate the strain or stress position located directly beneath the thin periderm and within the cortex. For both the wide and narrow trunks, the growth stresses at the basal and middle heights were mostly positive, indicating the existence of longitudinal tensile stresses at the cortical tissue of the trunk. However, the cortical growth stresses in the top parts of both narrow and wide trunks were negative, indicating the existence of longitudinal compressive stresses.

The internal growth strains and stresses of the central cylinder (open symbols) were calculated along the diameter of each diametrical plank at intervals of $1.5 \mathrm{~cm}$. Besides the basal part of the narrow palm, the growth stresses in the periphery of the outer part of the central cylinder were all negative, indicating the existence of compressive stress. The growth stress on the periphery of the central cylinder of the coconut palm trees 
resembled the compression wood of conifers. A similar finding was reported for rattan (Abasolo et al. 1999). In the inner part of the central cylinder, although there is mostly tensile stress, some compressive stresses were found. The values of the internal growth stresses generally increased from negative to positive and then decreased to around zero or to some negative, centripetally. The influence of the height of the stem on the amount of stress was not distinct in palm as opposed to the observation of Yao (1979) and Chafe (1985) on several dicotyledonous tree species.

In our first work on Cocos, the internal growth strains were studied only at the middle position of the trunk (Huang et al. 2002) and the measurements only had a slight variance. In the current study, the distribution of internal growth strains and stresses showed more complicated patterns somewhat related to the palm heights. At different heights, especially at the basal position of the narrow trunk, the internal growth strains and stresses showed positive patterns because they were highly related.

The complicated wavy form of internal growth stress distribution may partly result from the short internode of the trunks and the continual production of secondary cell wall layers during the palm tree growth. During fiber cell maturation, the secondary cell wall layers continue to accumulate in the cell wall, and the growth stresses may change.

There is a close relationship between the sample growth stresses of the trees and the fiber MFA. According to the measurements of surface strains in Cryptomeria japonica, Yamamoto et al. $(1988,1991)$ showed that where MFA is small, the longitudinal released microstrain is negative; otherwise, where MFA is large, the growth strains are positive. Based on the unified hypothesis, Guitard et al. (1999) applied the mechanical model to discuss the relationship between the growth strains and MFA. They calculated the critical MFA, at which the longitudinal growth strains changed from the negative to the positive values, at about $20-30^{\circ}$. In $\operatorname{Cocos}$ the average of MFA of the individual fiber $(n=300)$ in the peripheral central cylinder was $30.6 \pm 3.1^{\circ}$, which can explain the result of the compressive growth stress on the peripheral of the central cylinder.

The effects of angles of vascular bundles (macrostructure effects) and MFA in the fiber secondary cell wall (microstructure effects) on the growth stresses could act similar to the effects of angle of the tree's grain on the growth strains and stresses in hardwood and softwood trees (Archer 1987).

The distribution of internal growth stresses in woody palm trees is not as regular as in softwoods or hardwoods. In palm trees, the internal growth stresses at the same cross section of the trunk are initiated simultaneously; however, they change continuously thereafter with the maturation of cells and tissues during secondary thickening. In the central cylinder of palms, the vascular bundles are distributed sporadically and the maturation of cells and tissues is also diffuse. There is a balancing of the growth stresses in the ground tissue and the other cells nearby. At different positions of trunks (top, middle and base), the pattern of cell composition and distribution in the central cylinder were similar, but there were different proportions of the vascular bundles and fiber areas, and the internal growth stresses generated a different balance or adjustment above and below the zero line. 


\section{ACKNOWLEDGEMENTS}

The authors would like to thank Yi-Yin Hsieh, Ching-Yen Lin and Chih-Yuan Tong (Electron Microscope Laboratory of the College of Science, National Taiwan University) for assisting with the sample preparation. Thanks are also due to Dr. Chih-Lin Huang for critical reading and valuable suggestions and two anonymous reviewers for important comments and improvements.

\section{REFERENCES}

Abasolo, W., M. Yoshida, H. Yamamoto \& T. Okuyama. 1999. Internal stress generation in rattan canes. IAWA J. 20: 45-48.

Archer, R. R. 1987. Growth stresses and strains in trees: 102-107. Springer-Verlag, Berlin, Heidelberg.

Archer, R.R. \& F.E. Bynes. 1974. On the distribution of tree growth stresses. 1. An anisotropic plane strain theory. Wood Sci. Technol. 8: 184-196.

Bamber, R.K. 1978. The origin of growth stresses. In: Proc. IUFRO Conf. FORPRIDECOM, College, Laguna, Philippines: 1-7.

Bhat, K.M., W. Liese \& U. Schmitt. 1990. Structural variability of vascular bundles and cell wall in ratten stem. Wood Sci. Technol. 24: 211-224.

Boyd, J.D. 1972. Tree growth stresses. V. Evidence of an origin in differentiation and lignification. Wood Sci. Technol. 6: 251-262.

Chafe, S.C. 1985. Variation in longitudinal growth stress with height in trees of Eucalyptus nitens. Austral. For. Res. 15: 51-56.

Cho, C.H., T.P. Lin \& L.L. Kuo-Huang. 2001. Ultrastructural study on the recalcitrant seeds of Machilus thunbergii Sieb. \& Zucc. Taiwania 46: 125-134.

Fournier, M., P. A. Bordonne, D. Guitard \& T. Okuyama. 1990. Growth stress patterns in tree stems. Wood Sci. Technol. 24: 131-142.

Guitard, D., H. Masse, H. Yamamoto \& T. Okuyama. 1999. Growth stress generation: a new mechanical model of dimensional change of wood cells during maturation. J. Wood Sci. 45: 384-391.

Huang, C.L., N.P. Kutscha, G. J. Leaf \& R. A. Megraw. 1997. Comparison of microfibril angle measurement techniques. In: B. G. Butterfield (ed.), Microfibril angle in wood: 177-205. University of Canterbury, New Zealand.

Huang, Y. S., S. S. Chen, T.P. Lin \& Y.S. Chen. 2001. Growth stress distribution in leaning trunks of Cryptomeria japonica. Tree Physiol. 21: 261-266.

Huang, Y. S., S. S. Chen, T.P. Lin \& Y. S. Chen. 2002. Growth strain in coconut palm trees. Tree Physiol. 22: 261-266.

Kollmann, F. \& W. A. Côté, Jr. 1968. Principles of wood science and technology. I. Solid wood: 306-413. Springer-Verlag, New York.

Kubler, H. 1987. Growth stresses in trees and related wood properties. For. Abstracts 10: 61118.

Mattheck, C. \& H. Kubler. 1995. Wood: the internal optimization of trees: 63-89. Springer-Verlag, New York.

Niklas, K. J. 1992. Plant biomechanics: an engineering approach to plant form and function: 420-423. The University of Chicago Press.

Okuyama, T., A. Kawai, Y. Kikata \& H. Yamamoto. 1986. The growth stresses in reaction wood. In: Proc. XVIII IUFRO World Congress, Yugoslavia: 249-260.

Okuyama, T., Y. Sasaki, Y. Kikata \& N. Kawai. 1981. The seasonal change in growth stress in the tree trunk. Mokuzai Gakkaishi 27: 350-355.

Rich, P.M. 1987. Mechanical structure of the stem of arborescent palms. Bot. Gaz. 148: 42-50. 
Sasaki, Y., T. Okuyama \& Y. Kikata. 1978. The evolution process of the growth stress in the tree: the surface stress on the tree. Mokuzai Gakkaishi 24: 149-157.

Tomlinson, P. B. 1990. The structural biology of palms: 167-170. Clarenden Press, Oxford.

Tomlinson, P. B. \& M.H. Zimmermann. 1967. The "wood" of monocotyledons. IAWA Bull. n.s. 2: 4-24.

Wangaard, F.F. \& A.F. Muschler. 1952. Properties and uses of tropical woods. III. Trop. Woods 98: 1-193.

Yamamoto, H. \& T. Okuyama. 1988. Analysis of the generation process of growth stresses in cell walls. Mokuzai Gakkaishi 34: 788-793.

Yamamoto, H., T. Okuyama, M. Yoshida \& K. Sugiyama. 1991. Generation process of growth stresses in cell walls. Growth stress in compression wood. Mokuzai Gakkaishi 37: 94-100.

Yao, J. 1979. Relationship between height and growth stresses within and among white ash, water oak and shagbark hickory. Wood Sci. 11: 246-251. 